\title{
Time independent seismic hazard analysis of Greece deduced from Bayesian statistics
}

\author{
T. M. Tsapanos ${ }^{1}$, G. A. Papadopoulos ${ }^{2}$, and O. Ch. Galanis ${ }^{1}$ \\ ${ }^{1}$ Aristotle University of Thessaloniki, School of Geology, Geophysical Laboratory, 54006 Thessaloniki, Greece \\ ${ }^{2}$ Institute of Geodynamics, National Observatory of Athens, 11810 Athens, Greece
}

Received: 25 January 2002 - Revised: 2 September 2002 - Accepted: 20 September 2002

\begin{abstract}
A Bayesian statistics approach is applied in the seismogenic sources of Greece and the surrounding area in order to assess seismic hazard, assuming that the earthquake occurrence follows the Poisson process. The Bayesian approach applied supplies the probability that a certain cut-off magnitude of $M_{s}=6.0$ will be exceeded in time intervals of 10,20 and 75 years. We also produced graphs which present the different seismic hazard in the seismogenic sources examined in terms of varying probability which is useful for engineering and civil protection purposes, allowing the designation of priority sources for earthquake-resistant design. It is shown that within the above time intervals the seismogenic source (4) called Igoumenitsa (in NW Greece and west Albania) has the highest probability to experience an earthquake with magnitude $M \geq 6.0$. High probabilities are found also for Ochrida (source 22), Samos (source 53) and Chios (source 56).
\end{abstract}

\section{Introduction}

A large number of models are currently available for the assessment of seismic hazard. The objective in seismic hazard modeling is to obtain long term probabilities of occurrence of seismic events of specific size in a given time interval.

The Bayesian formalism allows the solution of problems which otherwise would be unapproachable. Benjamin (1968), assuming the Poisson distribution was the first who dealt with a Bayesian approach for the probabilistic description of the earthquake occurrence. Chou et al. (1971), presented a similar application based on different distributions. Mortgat and Shah (1979) presented a Bayesian model, for seismic hazard mapping, which takes into account the geometry of the faults in the investigated area, while Campbell (1982 and 1983) proposed a Bayesian extreme value distribution of earthquake occurrence to evaluate the seismic hazard along the San Jacinto fault. A similar procedure have

Correspondence to: T. M. Tsapanos (tsapanos@geo.auth.gr) been applied by Stavrakakis and Tselentis (1987) for a probabilistic prediction of strong earthquakes in Greece. Ferraes $(1985,1986)$ used a Bayesian analysis to predict the interarrival times for strong earthquakes along the Hellenic arc, as well as for Mexico. An alternative view of Ferraes research is made by Papadopoulos (1987) for the occurrence of large shocks in the east and west side of the Hellenic arc. A Bayesian approach of estimating the maximum values of the seismic peak ground acceleration at a considered site is presented by Pisarenko and Lyubushin (1997), while Lamarre et al. (1992) made an effort for a realistic evaluation of seismic hazard.

Greece is one of the most seismically active regions of the world. Ranking fifty seismogenic countries of the world Greece takes the sixth position (Tsapanos and Burton, 1991). Papazachos (1990) found that the most probable annual maximum magnitude of the shallow earthquakes in Greece is $\bar{M}=6.3$ while Papadopoulos and Kijko (1991) showed that the mean return periods of the shallow main shocks of $M_{s}=6.0$ and $M_{s}=6.5$ are around 1.7 years and 13 years, respectively. The seismotectonics in Greece and the adjacent regions is rather complex and, therefore, seismic hazard has been assessed on the basis of several approaches. The earthquake parameters used to describe the seismic hazard include maximum expected macroseismic intensity (Shebalin et al., 1976; Papaioannou, 1984), peak ground acceleration or velocity (Algemissen et al., 1976; Makropoulos and Burton, 1985), duration of the strong ground motion (Margaris et al., 1990; Papazachos et al., 1992) and maximum expected magnitude in conjunction with the return period of events of certain magnitude (Papadopoulos and Kijko, 1991). The geographical distribution of seismic hazard in Greece based on zonation of seismic sources was approached by Papazachos et al. (1993). Methods incorporating Bayesian statistics were applied by Stavrakakis (1985), Papadopoulos (1988, 1990), Pisarenko et al. (1996), and Stavrakakis and Drakopoulos (1995).

In this paper we test a time independent Bayesian approach (Benjamin, 1968) that yields the probability that a 


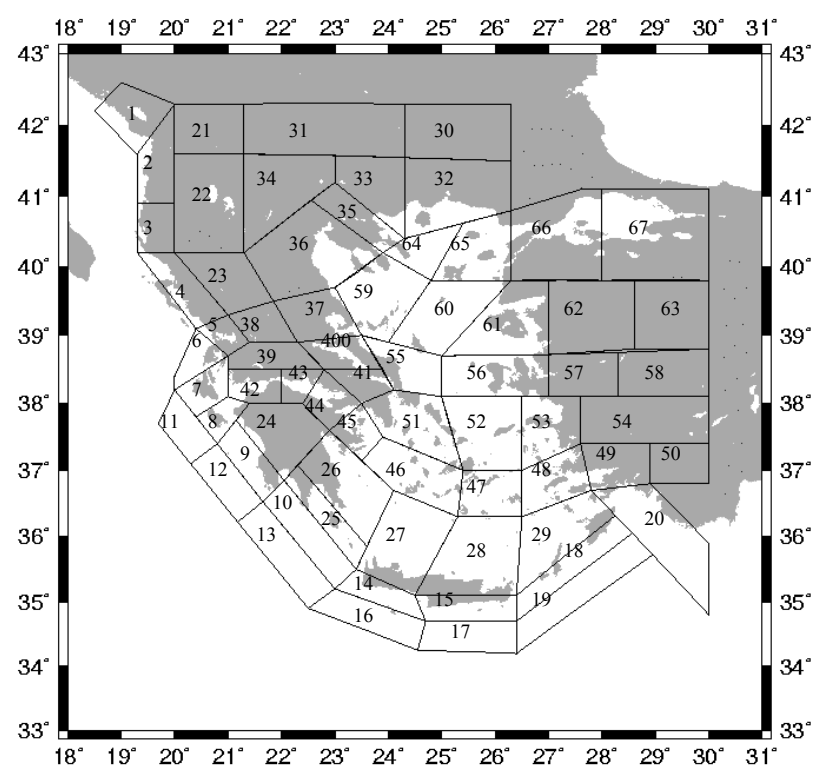

Fig. 1. Seismogenic sources of Greece and the surrounding area according to Papaioannou and Papazachos (2000).

certain cut-off magnitude will be exceeded in certain time intervals, a method that was not tested in the past in the seismogenic area of Greece. The method was tested on a new earthquake catalogue (Papazachos et al., 2000) and on the seismic zonation presented recently by Papaioannou and Papazachos (2000). We also produced graphs which present the different seismic hazard behavior in the examined seismogenic sources. The source-dependent probability of exceedance, as an expression of seismic hazard, was also estimated.

\section{Data set and the seismogenic sources}

Information about the seismicity of Greece exists since the 6th century B.C. However, most of the existing data banks suffer from that they do not fulfil the basic properties completeness, homogeneity, and accuracy required for a reliable estimation of various seismic parameters. Recently, an updated earthquake catalogue was compiled by Papazachos et al. (2000) (which is also presented in http://geohazards.cr. usgs.gov/iaspei/europe/greece/the/catalog.htm) in an effort to increase completeness, homogeneity and accuracy. Given that we are interested for the strong earthquake activity, we used only the part of the catalogue covering the time interval $1845-1999$, which it is likely complete for $M=6.0$. The errors involved in the magnitudes are in the interval of \pm 0.25 for the instrumental period (1911-1999). For the historical data these errors are \pm 0.35 when the number of available macroseismic points of observations is greater than 10 . When the number of observation points is less than 10 the magnitude errors reach up to a half magnitude unit. The epicenter coordinates for the earthquakes of the period 1965-
1999 have been calculated by instrumental data and their errors are up to $20 \mathrm{~km}$ for the older ones (1965-1980) and up to $10 \mathrm{~km}$ for the more recent ones (1981-1999). These coordinates for the period 1901-1964 were calculated by both instrumental and macroseismic information and their errors reach up to $30 \mathrm{~km}$. For the historical earthquakes the epicenters have usually an error of about $30 \mathrm{~km}$ but this may go up to $50 \mathrm{~km}$ when the number of available observation points is less than 5. Typical shallow earthquakes in the studied area have a focal depth of less than $20 \mathrm{~km}$, with the exception of events occurring along the Hellenic arc where depths can reach up to $50 \mathrm{~km}$. Seismicity of intermediate focal depth also occurs in the South Aegean Sea. However, the present study is restricted to shallow seismicity only. Aftershocks were eliminated, applied the procedure proposed by Gardner and Knopoff (1974) while the foreshocks removed by taking into account the critirion suggested by Jones and Molnar (1976). In this way only main shocks considered for the purpose of the present study.

Seismic zonation is one of the major problems in the very complex area of Greece. Papaioannou and Papazachos (2000) proposed a new regionalization of the shallow seismogenic sources which is based on historical and instrumental earthquake location data and on the stress field pattern as derived from reliable fault plane solutions. Thus, the whole Greece and the surrounding area was divided in 67 different seismogenic sources (Fig. 1). In the present study we adopted the above seismic zonation.

\section{Method applied}

We assume a Poisson distribution for the number of earthquake events $n$ that occur in a time interval $t$. Then the probability function is:

$P(n, t \mid v)=\frac{(v t)^{n} e^{-v t}}{n !}$,

where the positive parameter $v$, is the mean rate of earthquake occurrence. Suppose that in a given seismic source $n_{0}$ events occurred in $t_{0}$ years, which is the time length of the catalogue. The likelihood function is:

$l(v)=P\left(n_{0}, t \mid v\right)=\frac{\left(v t_{0}\right)^{n_{0}} e^{-v t_{0}}}{n_{0} !}$.

It is reminded that likelihood is the probability of the specific outcome to occur, that is the probability for exactly $n_{0}$ earthquakes to occur in the $t_{0}$ years covered by the catalogue, as a function of the mean rate of occurrence.

The prior distribution for $v, f^{\prime}(v)$ is assumed to be uniform. This is equivalent to stating that the mean rate of occurrence can have any value, as long as it is not negative, with the same probability. From the Bayesian theory, its posterior distribution, will be:

$f^{\prime \prime}(v)=c f^{\prime}(v) L(v)$, 
Table 1. Probability of exceedance of magnitude 6.0 in 10,20 and 75 years, $n_{o}$ denotes the number of mainshocks with magnitude $M \geq 6.0$

\begin{tabular}{|c|c|c|c|c|}
\hline \multirow{2}{*}{$\begin{array}{l}\text { mainshocks, } M \geq 6.0 \\
\text { Names of sources }\end{array}$} & \multirow[b]{2}{*}{$n_{o}$} & \multicolumn{3}{|c|}{ Probability of exceedance in: } \\
\hline & & 10 years & 20 years & 75 years \\
\hline Source 1 Montenegro & 2 & 0.171 & 0.305 & 0.694 \\
\hline Source 2 Dyrrachium & 4 & 0.268 & 0.455 & 0.861 \\
\hline Source 3 Avlona & 7 & 0.394 & 0.621 & 0.957 \\
\hline Source 4 Igoumenitsa & 10 & 0.497 & 0.737 & 0.987 \\
\hline Source 5 Preveza & 3 & 0.221 & 0.385 & 0.794 \\
\hline Source 6 Leukada & 5 & 0.313 & 0.517 & 0.906 \\
\hline Source 7 Cephalonia & 7 & 0.394 & 0.621 & 0.957 \\
\hline Source 8 Zante & 7 & 0.394 & 0.621 & 0.957 \\
\hline Source 9 Pylos & 6 & 0.354 & 0.572 & 0.937 \\
\hline Source 10 Mane & 1 & 0.118 & 0.216 & 0.546 \\
\hline Source 11 Ionian Sea 1 & 3 & 0.221 & 0.385 & 0.794 \\
\hline Source 12 Ionian Sea 2 & 0 & 0.061 & 0.114 & 0.326 \\
\hline Source 13 Ionian Sea 3 & 2 & 0.171 & 0.305 & 0.694 \\
\hline Source 14 SW Crete & 6 & 0.354 & 0.572 & 0.937 \\
\hline Source 15 SE Crete & 1 & 0.118 & 0.216 & 0.546 \\
\hline Source 16 Libyan Sea 1 & 2 & 0.171 & 0.305 & 0.694 \\
\hline Source 17 Libyan Sea 2 & 1 & 0.118 & 0.216 & 0.546 \\
\hline Source 18 Karpathos & 3 & 0.221 & 0.385 & 0.794 \\
\hline Source 19 Strabo & 1 & 0.118 & 0.216 & 0.546 \\
\hline Source 20 Marmaris & 6 & 0.354 & 0.572 & 0.937 \\
\hline Source 21 Piskope & 1 & 0.118 & 0.216 & 0.546 \\
\hline Source 22 Ochrida & 9 & 0.465 & 0.703 & 0.981 \\
\hline Source 23 Drosopighe & 6 & 0.354 & 0.572 & 0.937 \\
\hline Source 24 Tripolis & 5 & 0.313 & 0.517 & 0.906 \\
\hline Source 25 Cythera & 4 & 0.268 & 0.455 & 0.861 \\
\hline Source 26 Leonidi & 0 & 0.061 & 0.114 & 0.326 \\
\hline Source 27 NW Crete & 0 & 0.061 & 0.114 & 0.326 \\
\hline Source 28 NE Crete & 2 & 0.171 & 0.305 & 0.694 \\
\hline Source 29 Rhodos & 3 & 0.221 & 0.385 & 0.794 \\
\hline Source 30 Philipoupole & 1 & 0.118 & 0.216 & 0.546 \\
\hline Source 31 Kresna & 4 & 0.268 & 0.455 & 0.861 \\
\hline Source 32 Drama & 0 & 0.061 & 0.114 & 0.326 \\
\hline Source 33 Serres & 1 & 0.118 & 0.216 & 0.546 \\
\hline Source 34 Ptolemais & 3 & 0.221 & 0.385 & 0.794 \\
\hline Source 35 Volve & 3 & 0.221 & 0.385 & 0.794 \\
\hline Source 36 Kozane & 3 & 0.221 & 0.385 & 0.794 \\
\hline Source 37 Thessalia & 5 & 0.313 & 0.517 & 0.906 \\
\hline Source 38 Cremasta & 1 & 0.118 & 0.216 & 0.546 \\
\hline Source 39 Agrinio & 1 & 0.118 & 0.216 & 0.546 \\
\hline Source 40 Maliakos & 1 & 0.118 & 0.216 & 0.546 \\
\hline Source 41 Thebes & 6 & 0.354 & 0.572 & 0.937 \\
\hline Source 42 Patra & 1 & 0.118 & 0.216 & 0.546 \\
\hline Source 43 Aeghio & 7 & 0.394 & 0.621 & 0.957 \\
\hline Source 44 Corinth & 6 & 0.354 & 0.572 & 0.937 \\
\hline Source 45 Methana & 1 & 0.118 & 0.216 & 0.546 \\
\hline Source 46 Melos & 1 & 0.118 & 0.216 & 0.546 \\
\hline Source 47 Thera & 2 & 0.171 & 0.305 & 0.694 \\
\hline Source 48 Cos & 2 & 0.171 & 0.305 & 0.694 \\
\hline Source 49 Alikarnassos & 4 & 0.268 & 0.455 & 0.861 \\
\hline Source 50 Denisli & 1 & 0.118 & 0.216 & 0.546 \\
\hline Source 51 S. Euboikos Gulf & 1 & 0.118 & 0.216 & 0.546 \\
\hline Source 52 Ikaria & 1 & 0.118 & 0.216 & 0.546 \\
\hline Source 53 Samos & 9 & 0.465 & 0.703 & 0.981 \\
\hline Source 54 Aydin & 3 & 0.221 & 0.385 & 0.794 \\
\hline Source 55 Kyme & 0 & 0.061 & 0.114 & 0.326 \\
\hline
\end{tabular}

Table 1. continued

\begin{tabular}{lcccc}
\hline \multirow{2}{*}{ mainshocks, $M \geq 6.0$} & \multicolumn{4}{c}{ Probability of exceedance in: } \\
Names of sources & $n_{o}$ & 10 years & 20 years & 75 years \\
\hline Source 56 Chios & 9 & 0.465 & 0.703 & 0.981 \\
Source 57 Izmir & 5 & 0.313 & 0.517 & 0.906 \\
Source 58 Alashehir & 1 & 0.118 & 0.216 & 0.546 \\
Source 59 Skiathos & 7 & 0.394 & 0.621 & 0.957 \\
Source 60 Skyros & 3 & 0.221 & 0.385 & 0.794 \\
Source 61 Lesbos & 5 & 0.313 & 0.517 & 0.906 \\
Source 62 Demirci & 5 & 0.313 & 0.517 & 0.906 \\
Source 63 Gediz & 4 & 0.268 & 0.455 & 0.861 \\
Source 64 Athos & 3 & 0.221 & 0.385 & 0.794 \\
Source 65 Samothrace & 6 & 0.354 & 0.572 & 0.937 \\
Source 66 Hellespont & 6 & 0.354 & 0.572 & 0.937 \\
Source 67 Brussa & 7 & 0.394 & 0.621 & 0.957 \\
\hline
\end{tabular}

where $c$ is a constant such that the resulting function can be a probability density function, that is:

$$
\int_{0}^{+\infty} f^{\prime \prime}(v) d v=1
$$

Now, observe that because $f^{\prime \prime}(v)$ is independent of $v$, the factor $k=c f^{\prime}(v)$ is constant, so that Eq. (3) can be rewritten as:

$$
f^{\prime \prime}(v)=k L(v)=k \frac{\left(v t_{0}\right)^{n_{0}} e^{-v t_{0}}}{n_{0} !} .
$$

This expression is normalized for $k=t_{0}$. Now consider the posterior probability of $n$ events occurring in $t$ years. This will be the probability $P(n, t \mid v)$ weighted in respect to the posterior distribution of $v$ :

$$
\begin{aligned}
& P^{\prime \prime}(n, t)=\int_{0}^{\infty} P(n, t \mid v) f^{\prime \prime}(v) d v= \\
& \int_{0}^{\infty} \frac{(v t)^{n} e^{-v t}}{n !} \frac{t_{0}\left(v t_{0}\right)^{n_{0}} e^{-v t_{0}}}{n_{0} !} d v .
\end{aligned}
$$

Integration yields (Benjamin, 1968):

$$
P^{\prime \prime}(n t)=\frac{\left(n+n_{0}\right) !}{n ! n_{0} !} \frac{\left(t / t_{0}\right)^{n}}{\left(1+1 / t_{0}\right)^{n+n_{0}+1}} .
$$

Applying Eq. (7), the posterior probability of no events occurring in $t$ years is:

$P(0, t)=\left(1+t / t_{0}\right)^{-n_{0}-1}$.

Therefore, the probability of exceedance of a selected lower magnitude, $M_{o}$, that is the probability of at least one event of $M \geq M_{o}$ occurring in the next $t$ years is:

$\bar{P}(0, t)=1-\left(1+t / t_{0}\right)^{-n_{0}-1}$. 
(a)

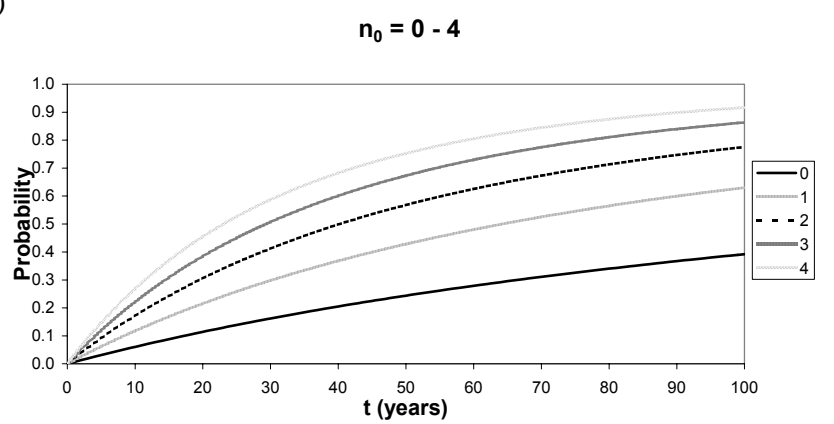

(b)

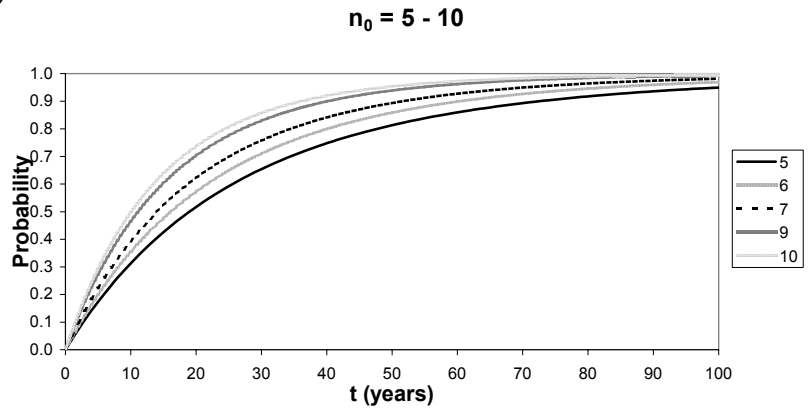

Fig. 2. Probabilities of exceedance of magnitude 6.0 in the range 1 to 100 years for (a) the Greek seismogenic sources with $n_{o}=0-4$ and (b) the Greek seismogenic sources with $n_{o}=5-10$.

From the above formula we computed the probabilities of exceedance of the magnitude $M_{o}=6.0$ in the 67 Greek seismogenic sources at any time interval ranging from 1 to 100 years.

\section{Results}

The results obtained are shown in Table 1 and in Fig. 2. Table 1 includes the names of the seismic sources examined along with their corresponding code numbers (according to Papaioannou and Papazachos, 2000). In addition, Table 1 shows the number of shocks, $n_{o}$, with magnitude $M \geq 6.0$ that were taken into account for the probability calculation, as well as the probability of exceedance in 10,20 and 75 years. The first two time intervals are within the range usually considered in the long-term earthquake prediction (e.g. Nishenko, 1985; Papazachos et al., 1987) while the time interval of 75 years is of engineering interest because it is almost equal to the life time of the ordinary buildings. Also Papazachos et al. (1987) considered that the time interval of 20 years is more appropriate on the basis that the probability calculations are often more stable than they are for shorter intervals. In five of the seismic sources the number $n_{o}$ of the seismic events equals to 0 , which is not true but means that events occurred only before 1845 when our data set begins. It was decided that this fact constitutes useful information, which could be input to the estimation of probabilities of occurrence of actual earthquakes by means of the Bayes theorem. In fact, this information can set an upper limit to the probability of occurrence of earthquakes, since it provides a lower limit to the time period during which no earthquakes occurred.

The source dependence of the exceedance probabilities listed in Table 1. We observed that all the sources belonged in one of 10 cases (where $n_{o}=0,1,2,3,4,5,6,7,9$ and 10). There is no source with $n_{o}=8$. We can grouped the 10 cases in those where $n_{o}=0-4$ (Fig. 2a), while in the other group $n_{o}=5-10$ (Fig. 2b). It is interesting to observe that the statistical behavior of the two groups is different, where the group $n_{o}=0-4$ shows lower probability values than the other group with $n_{o} \geq 5$. In general Fig. 2 allows for a better visual inspection of the geographical probability distribution. It is clear that the source 4 (Igoumenitsa) has the highest probability to experience an earthquake with $M \geq 6.0$ in the next 10, 20 and 75 years. The second highest probability is estimated for Ochrida (source 22), Samos (source 53), and Chios (source 56), while high probabilities are also assessed for the sources 3, 7, 8, 43, 59 and 67 .

Plots of the probabilities of exceedance for time periods ranging from 1 to 100 years (Fig. 3) shows that in about one third of the seismic sources, namely in those with code numbers $3,4,6,7,8,9,14,20,22,23,41,43,44,53,56,57$, $59,62,65,66$ and 67 , very high probabilities were found for an earthquake occurrence of magnitude $M \geq 6.0$ in the next 100 years, while in the rest sources probability varies from low to high.

\section{Discussion}

The hazard computation in the present study assumes a random (Poisson) distribution of earthquakes in time, which is a good approximation with long, quasi-random time windows of earthquake occurrence. It is considered as a conservative assumption appropriate for building design.

Papazachos et al. (1987), based on the assumption that the repeat time of earthquakes follow the Gaussian distribution, presented a map of conditional probabilities for the occurrence of shallow earthquakes with $M \geq 6.5$ in the period 1986-2006. Results of that study are only partly comparable with those obtained by us because in our data set we also took into account strong earthquakes that occurred in the last fifteen years (1986-1999), a time interval which is not considered by Papazachos et al. (1987) because in their study they dealt with data up to 1986 . They also used a model which has a memory. For this reason contradictory results were obtained. For example, according to Papazachos et al. (1987) the source 43 (Aeghio) was of high probability $(0.80-1.00)$, while for the time span of 20 years we calculated relatively high $(0.62)$ probability. This is due to the method used, as well as to the fact that the strong Aeghio earthquake $\left(M_{w}=6.4\right)$ of 15 June 1995 occurred after the presentation of the results of Papazachos et al. (1987) and before the performance of our calculations. Our method applied is based on the memoryless Poisson model. In other words the probabilities estimated before and after, for in- 
(a)

\section{Probability of exceedance $M \geq 6.0$ in 10 years}

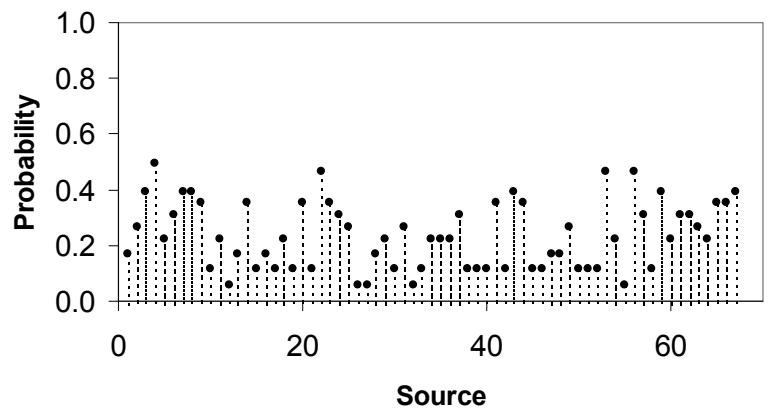

(b)

Probability of exceedance $M \geq 6.0$ in 20 years

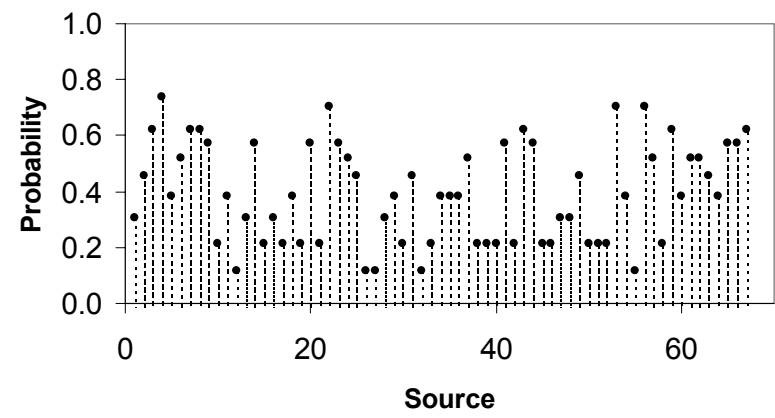

(c)

Probability of exceedance $M \geq 6.0$ in 75 years

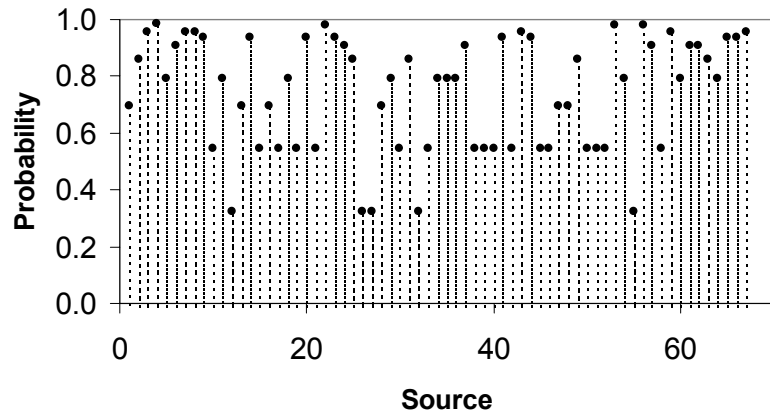

Fig. 3. Distribution of the probability of exceedance of magnitude 6.0 in (a) 10 , (b) 20 and (c) 75 years examined in the 67 seismogenic sources.

stance, the event of 1995 in Aeghion area (source 43) are almost the same. A small test is applied for this source and the earthquake of 1995 . We considered all shocks from 18451985 (the time span for which Papazachos et al. took for the study of 1987) with magnitudes $M \geq 6.0$. The probability we found for these 140 years is 0.654 . Taking into account and the event of 1995 and re-evaluated the probabilities now for 150 years (1845-1999) we found a probability 0.621 , which is in accordance with what method describes; almost equal probabilities before and after a strong event. Nevertheless, some of the areas determined by Papazachos et al. (1987) of being of very high probability are identical with the sources 4, 6, 7, and 31 determined in the present study as the most likely to experience an earthquake in the next 20 years. Moreover, Papazachos and Papaioannou (1993) based on a time dependent model, investigated the long-term earthquake prediction for the time interval 1993-2002. Although their approach is not based on the memoryless Poisson process some of their results are in good agreement with the results obtained in the present study (e.g. sources 4, 56, 67).

The Bayesian approach as was indicated can be applied to any hazard analysis. A method recently elaborated by $\mathrm{Pa}-$ paioannou and Papazachos (2000) for seismic hazard assessment in Greece, based on both time dependent and time independent models, can not be adopted for comparison purposes given that intensities instead of magnitudes were applied.

The results obtained in the present paper are strongly sensitive to the seismic zonation adopted. In fact, the geographical extent of the seismic sources is very small and therefore, a change in the zonation results in the shift of some earthquake events from one seismic source to another, thus influencing the number of events incorporated in each source and consequently the seismic hazard. This becomes more realistic if we take in account the error in the epicenter of the earthquakes (see Sect. 2) and apply this error especially to those earthquakes which occurred very close to the bounds of adjacent sources. In order to avoid this inconsistency supplementary information were considered (e.g. macroseismic observations). Thus we secured the place (source) of the occurrence of an earthquake. Another bad influence could be the error in the determination of the earthquakes magnitude, whereas an error of \pm 0.2 magnitude units, could change the number of earthquakes in each source which exceeding the lower magnitude threshold considered. We must notice here that it is more important to look at the relative levels of probability with respect to adjacent sources, than the absolute level in any single source. It seems that a physical interaction exists between these sources, where the occurrence of a strong $(M \geq 6.0)$ earthquake in one can disturb the stress field in the adjacent sources. In this way the time-independent approach seems more appropriate for the present study. Objective seismic zonation is still a major problem in the complex seismotectonic environment of Greece with important consequences in the reliable assessment of the seismic hazard.

Acknowledgements. The authors like to express their sincere thanks to R. Console and the unknown reviewer for the fruitful criticism of the paper.

\section{References}

Algermissen, S. T., Perkins, D. M., Issherwood, W., Gordon, D., Reagor, G., and Howard, C.: Seismic risk evaluation of the Balkan region, Proc. Sem. Seismic Zoning Maps, UNESCO, Skopje 1975, 2, 68-171, 1976.

Benjamin, J. R.: Probabilistic models for seismic forces design, Struct. Div., ASCE 94, 5T5, 1175-1196, 1968.

Campbell, K. W.: Bayesian analysis of extreme earthquake occurrences, Part I. Probabilistic hazard model, Bull. Seismol. Soc. Am., 72, 1689-1705, 1982. 
Campbell, K. W.: Bayesian analysis of extreme earthquake occurrences, Part II. Application to the San Jacinto fault zone of southern California, Bull. Seismol. Soc. Am., 73, 1099-1115, 1983.

Chou, I. H., Zimmer, W. J., and Yao, J. T. P.: Likelihood of strong motion earthquakes, Bureau of Engineering Research, University of New Mexico, Technical Report CE 27, 71, 1971.

Ferraes, S. G.: The Bayesian probabilistic predictions of strong earthquakes in the Hellenic arc, Tectonophysics, 111, 339-354, 1985

Ferraes, S. G.: Bayes theorem and probabilistic prediction of interarrival times for strong earthquakes felt in Mexico city, J. Phys. Earth, 34, 71-83, 1986.

Jones, L. and Molnar, P.: Frequency of foreshocks, Nature, 262, 677-679, 1976

Gardner, J. K. and Knopoff, L.: Is the sequence of earthquakes in Southern California with aftershocks removed, Poissonian? Bull. Seismol. Soc. Am., 64, 1363-1367, 1974.

Lamarre, M., Townshed, B., and Shah, H. C.: Application of the bootstrap method to quantify uncertainty in seismic hazard estimates, Bull. Seismol. Soc. Am., 82, 104-119, 1992.

Makropoulos, K. C. and Burton, P. W.: Seismic hazard in Greece, II Ground acceleration, Tectonophysics, 117, 259-294, 1985.

Margaris, V. N., Theodooulidis, N. P., Papaioannou, Ch. A., and Papazachos, B. C.: Strong motion duration of earthquakes in Greece, Proc. XXII Gen. Ass. E.S.C., 2, 865-871, 1990.

Mortgat, C. P. and Shah, H. C.: A Bayesian model for seismic hazard mapping, Bull. Seismol. Soc. Am., 69, 1237-1251, 1979.

Nishenko, S. P.: Seismic potential for large and great interplate earthquakes along the Chilean and southern Perouvian margins of south America: a quantitative reappraisal, J. Geophys. Res., 90, 3589-3615, 1985.

Papadopoulos, G. A.: An alternative view of the Bayesian probabilistic prediction of strong shocks in the Hellenic arc, Tectonophysics, 132, 311-320, 1987.

Papadopoulos, G. A.: Statistics of historical earthquakes and associated phenomena in the Aegean and surrounding regions, In: The Engineering Geology of ancient Works, Monuments and Historical Sites, Presentation and protection, (Eds) Marinos, P. G and koukis, G. C., Proc. Intern. Symp. organized by Greek National Group of IAEG, Athens, 19-23 September 1988, 1279-1283, 1988.

Papadopoulos, G. A.: Deterministic and stochastic models of the seismic and volcanic events in the Santorini volcano, Thera and the Aegean World Proc. of the 3rd Intern. Congr., (Ed) Hardy, D.A., 2 151-158, 1990.

Papadopoulos, G. A. and Kijko, A.: Maximum likelihood estimation of earthquake hazard parameters in the Aegean arc from mixed data, Tectonophysics, 185, 277-294, 1991.

Papaioannou, Ch. A.: Attenuation of seismic intensities and seismic hazard in the area of Greece, $\mathrm{Ph}$. D. Thesis, Univ. of Thessa- loniki, Thessaloniki, 200 pp., 1984.

Papaioannou, Ch. A. and Papazachos, B. C.: Time-independent and time-dependent seismic hazard in Greece based on seismogenic sources, Bull. Seismol. Soc. Am, 90, 22-33, 2000.

Papazachos, B. C.: Seismicity of the Aegean and surrounding area, Tectonophysics, 178, 287-308, 1990.

Papazachos, B. C. and Papaioannou, Ch. A.: Long-term earthquake prediction in the Aegean area based on a time and magnitude predictable model, Pageoph, 140, 593-612, 1993.

Papazachos, B. C., Papadimitriou, E. E., Kiratzi,, A. A., Papaioannou, Ch. A., and Karakaisis, G. F.: Probabilities of occurrence of large earthquakes in the Aegean and the surrounding area during the period 1986-2006, Pageoph., 125, 597-612, 1987.

Papazachos, B. C., Margaris, V. N., Theodoulidis, N. P., and Papaioannou, Ch. A.: Seismic hazard assessment in Greece based on strong motion duration, Proc. 10th W. C. E. E., 1, 425-430, 1992.

Papazachos, B. C., Papaioannou, Ch. A., Margaris, V. N., and Theodoulidis, N. P.: Regionalization of seismic hazard in Greece based on seismic sources, Natural Hazards, 8, 1-18, 1993.

Papazachos, B. C., Comninakis, P. E., Karakaisis, G. F. Karakostas, B. G., Papaioannou, Ch. A., Papazachos, C. B., and Scordilis, E. M.: A catalogue of earthquakes in Greece and surrounding area for the period 550B.C.-1999, Publ. of Geophys. Laboratory, Univ. of Thessaloniki, 2000.

Pisarenko, V. F., Lyubushin, A. A., Lysenko, V. B., and Golubeva, T. V.: Statistical estimation of seismic hazard parameters: maximum possible magnitude and related parameters, Bull. Seism. Soc. Am., 86, 691-700, 1996.

Pisarenko V. F. and Lyubushin, A. A.: Statistical estimation of maximal peak ground acceleration at a given point of seismic region, J. Seismology, 1, 395-405, 1997.

Shebalin, N. V., Reisner, G. I., Drumea, A. V., Aptekman, J. V., Sholpo, V. N., Stepaneks, N. Y., and Zacharova, A. J.: Earthquake origin zones distribution of maximum expected seismic intensity for the Balkan region, Proc. Sem. Seismic Zoning Maps, UNESCO, Skopje 1975, 2, 68-171, 1976.

Stavrakakis, G. N.: Contribution of Bayes statistics on the estimation of the seismic risk of the broad area of Crete island and the simulation of the expected strong ground motions, Ph. D. Thesis, Univ of Athens, Athens, 266 pp., 1985.

Stavrakakis, G. N. and Tselentis, G. A.: Bayesian probabilistic prediction of strong earthquakes in the main seismogenic zones of Greece, Boll. Geofis. Teor. Applic., 113, 51-63, 1987.

Stavrakakis, G. N. and Drakopoulos, J.: Bayesian probabilities of earthquake occurrences in Greece and surrounding areas, $\mathrm{Pa}$ geoph, 144, 307-319, 1995.

Tsapanos, T. M. and Burton, P. W.: Seismic hazard evaluation for specific seismic regions of the world, Tectonophysics, 194, 153$169,1991$. 